\title{
The Role of Kinetics as Key Determinant in Toxicity of Pyrrolizidine Alkaloids and Their $\mathrm{N}$-Oxides
}

\section{(ㄷ) (1) (우)}

\author{
Authors

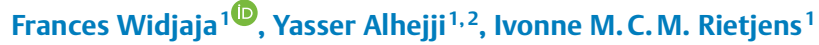

Affiliations

1 Division of Toxicology, Wageningen University and Research, The Netherlands

2 Department of Food Science and Human Nutrition, College of Agriculture and Veterinary Medicine, Qassim University, Buraydah, Saudi Arabia

Key words

Toxicokinetics, pyrrolizidine alkaloids, pyrrolizidine alkaloid $\mathrm{N}$-oxides, relative potency (REP) value, Physiologically-based kinetic (PBK) models received

accepted after revision

published online

Bibliography

Planta Med 2022; 88: 130-143

DOI 10.1055/a-1582-9794

ISSN 0032-0943

(C) 2021. The Author(s).

This is an open access article published by Thieme under the terms of the Creative Commons Attribution-NonDerivative-NonCommercial-License, permitting copying and reproduction so long as the original work is given appropriate credit. Contents may not be used for commercial purposes, or adapted, remixed, transformed or built upon. (https://creativecommons.org/licenses/by-nc-nd/4.0/)

Georg Thieme Verlag KG, Rüdigerstraße 14,

70469 Stuttgart, Germany
April 13, 2021

August 9, 2021

November 3, 2021
Correspondence

Prof. Dr. ir. Ivonne M. C. M. Rietjens

Wageningen University \& Research, Division of Toxicology

Stippeneng 4, 6708WE Wageningen, Netherlands

Phone: + 31317483971

ivonne.rietjens@wur.nl

Supplementary material is available under

https://doi.org/10.1055/a-1582-9794

\section{ABSTRACT}

Pyrrolizidine alkaloids (PAs) are a large group of plant constituents of which especially the 1,2- unsaturated PAs raise a concern because of their liver toxicity and potential genotoxic carcinogenicity. This toxicity of PAs depends on their kinetics. Differences in absorption, distribution, metabolism, and excretion (ADME) characteristics of PAs may substantially alter the relative toxicity of PAs. As a result, kinetics will also affect relative potency (REP) values. The present review summarizes the current state-of-the art on PA kinetics and resulting consequences for toxicity and illustrates how physiologicallybased kinetic (PBK) modelling can be applied to take kinetics into account when defining the relative differences in toxicity between PAs in the in vivo situation. We conclude that toxicokinetics play an important role in the overall toxicity of pyrrolizidine alkaloids. and that kinetics should therefore be considered when defining REP values for combined risk assessment. New approach methodologies (NAMs) can be of use to quantify these kinetic differences between PAs and their $\mathrm{N}$-oxides, thus contributing to the 3Rs (Replacement, Reduction and Refinement) in animal studies.

\section{Introduction}

Pyrrolizidine alkaloids (PAs) are a large group of plant constituents of which especially the 1,2-unsaturated PAs raise a concern because of their liver toxicity and potential genotoxic carcinogenicity. This toxicity of PAs is influenced by kinetics, and differences in absorption, distribution, metabolism, and excretion (ADME) characteristics of PAs may substantially alter the relative toxicity of
PAs. As a result, differences in kinetics will also influence relative potency (REP) values. Such REP values are required to take differences in potency between PAs into account in combined risk assessment [1].

Kinetics are of importance for the toxicity of 1,2-unsaturated PAs because these PAs require bioactivation to dehydroPAs to become toxic. Although the metabolic pathway for bioactivation of PAs is similar, there appear to be marked differences in kinetics 


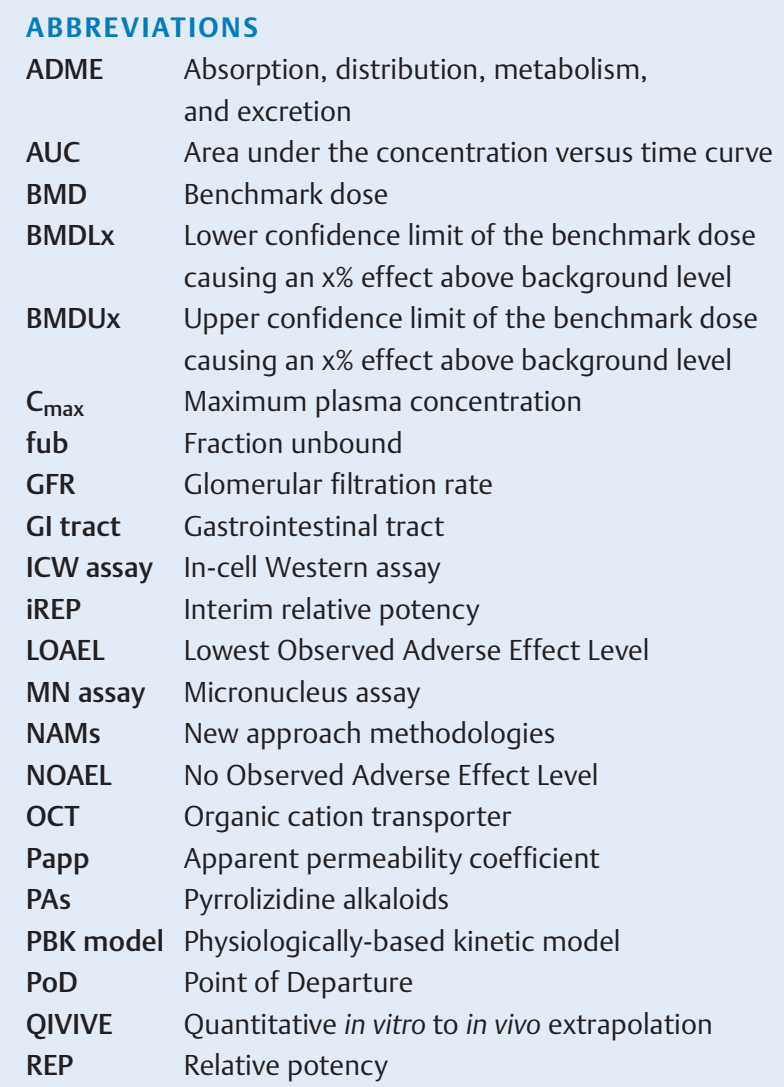

between PAs resulting in substantial variation in metabolic clearance and bioavailability. This implies that metabolism and thus kinetics are key determinants in PA toxicity. It also implies that the definition of REP values for in vivo risk assessment should take toxicokinetics into account. The present review summarizes the current state-of-the art on kinetics of PAs and resulting consequences for their toxicity and illustrates how physiologicallybased kinetic (PBK) modelling can be applied to take kinetics into account when defining the relative potencies for toxicity of PAs in the in vivo situation.

\section{Literature Search Strategy}

A literature search was performed using Google Scholar and PubMed using the Advanced Search feature, and the publication period set from 1950 to 2021 . Table $1 S$ in the supplementary materials presents an overview of the keywords used. It is noteworthy to highlight that each pyrrolizidine alkaloid has a distinct name; for that reason, the search was not limited to keywords found in the title but also included keywords anywhere in the article. For each search, the title of articles found in the first 10 web pages (100 most recent hits) were scanned and added to Endnote when considered relevant. Later, duplicates were removed, and the abstracts of the articles thus obtained were scanned for relevant information as part of the inclusion strategy. The snowballing effect was used to find additional articles to ascertain that rele- vant previous articles were also included, and after reviewing, 79 articles were selected.

\section{Differences in ADME Characteristics}

PAs may differ in their ADME characteristics; such differences may already become evident during absorption in the gastrointestinal tract. Some studies pointed at differences in the absorption of the PAs across the intestinal barrier. The intestinal uptake of PA-N-oxides, for example, was reported to be less efficient than that of the corresponding PAs [2]. Using Caco-2 monolayer cells, apparent permeability coefficient (Papp) values of tested PA-N-oxides were demonstrated to be low to moderate compared to those of tested PAs (• Fig. 1).

Furthermore, although the absorption of PAs may proceed via passive diffusion, there may also be a role for active transport depending on the type of PA. For example, the organic cation transporter 1 (OCT1) was reported to play a role in active transport of some PAs into the liver [3]. The substrates of OCT1 are known to be mainly organic cations, while some weak bases, non-charged compounds and anions are also transported [4]; especially retronecine-type PAs including monocrotaline and retrorsine were shown to be high affinity substrates of OCT1 [3,5]. At low $\mathrm{pH}$, where monocrotaline is protonated to its corresponding cation, transport by OCT1 even appeared to be dominant and passive diffusion was relatively negligible [3]. At higher $\mathrm{pH}$ values in the intestinal compartment $[6,7]$, a substantial part of monocrotaline would be neutral and transported via passive diffusion. The same study also revealed that in rat hepatocytes at $\mathrm{pH} 7.4$ the OCT1 mediated transport and passive diffusion may contribute equally to the intestinal absorption of monocrotaline [3].

Detailed studies on potential differences in characteristics for distribution of PAs have not been described so far. Yet, differences in, for example, lipophilicity, might cause variations in tissue distribution and protein binding, thereby influencing the unbound concentration of a PA available in the target tissue to induce toxicity. For example, PAs are known to be more lipophilic with higher log P octanol/water coefficients than their corresponding PA-Noxides [2], a characteristic potentially resulting in variations in distribution. To illustrate this, $>$ Table 1 lists the degree of protein binding, reflected by the fraction unbound (fub) and tissue partition coefficient values of various PAs and their $\mathrm{N}$-oxides in adipose and liver tissue. These values were calculated using the $\log P$ and molecular weight of the compounds, organ permeability and elimination rate constant of the tissue into plasma as previously described $[8,9]$. Compared to PAs, PA-N-oxides have lower log P and partition coefficient values in adipose but higher partition coefficient values in liver due to the higher fat content of adipose tissue than of liver tissue.

Lipophilicity could also play a role in the level of protein binding and, as a result, affect the excretion of PAs via glomerular filtration. The fub of PAs and PA-N-oxides in rat or human plasma can be determined based on their log $P$ and molecular weight, using the QIVIVE Tools (www.qivivetools.wur.nl) designed by Wageningen Food Safety Research $[9,10]$. Although log P values presented in $>$ Table 1 are below 5 and considered low [11], PAs generally have higher $\log \mathrm{P}$ values and consequently lower fub than their 


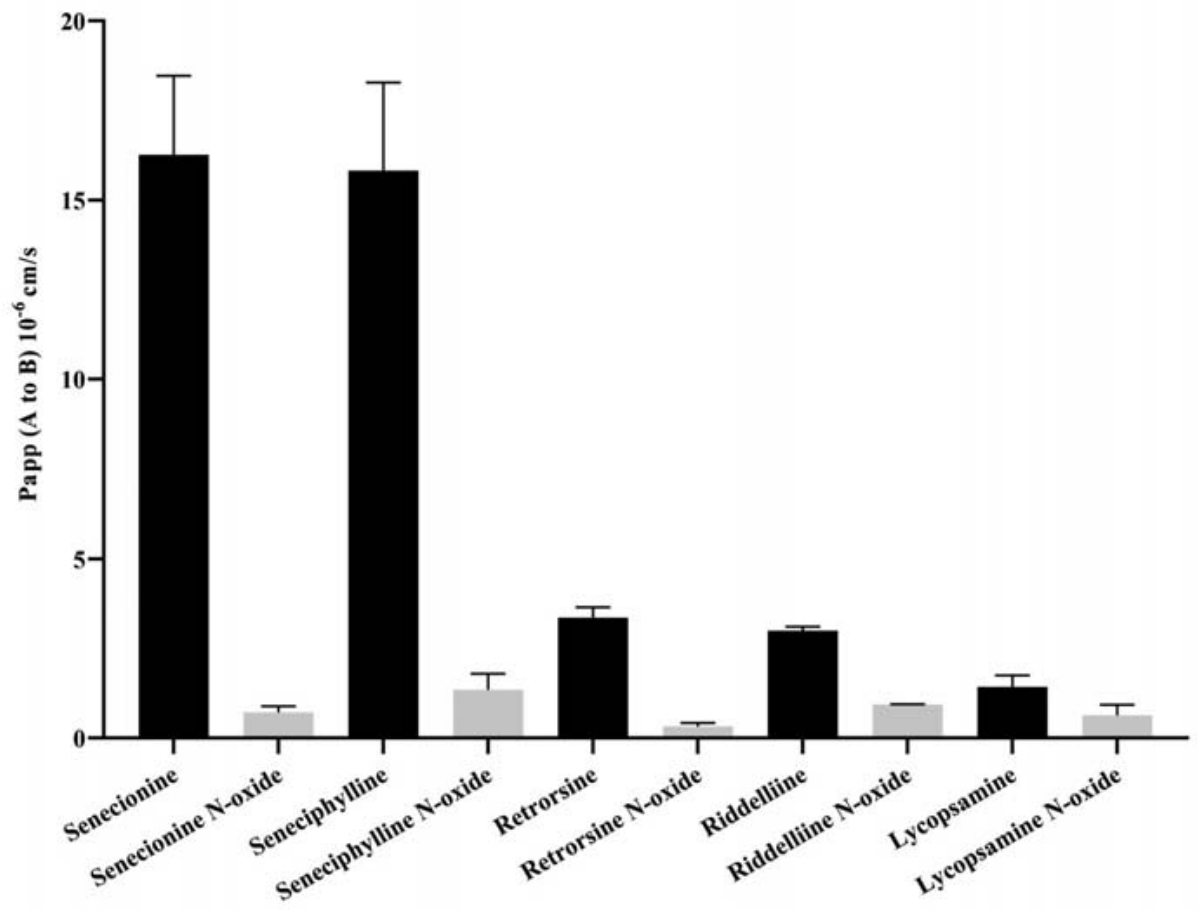

- Fig. 1 Apparent permeability coefficients (Papp) of PAs and their respective PA-N-oxides in Caco-2 monolayer cells ( $50 \mu \mathrm{M})$. Data were extracted from Yang et al. (2020).

- Table 1 Molecular weight (MW), lipophilicity (Log P), degree of protein binding reflected by the fraction unbound (fub) and partition coefficient of different PAs and corresponding PA N-oxides.

\begin{tabular}{|c|c|c|c|c|c|}
\hline & \multirow[t]{2}{*}{ Mw } & \multirow[t]{2}{*}{$\log P^{a}$} & \multirow[t]{2}{*}{$f_{u b}^{b}$} & \multicolumn{2}{|c|}{ Partition coefficient value ${ }^{c}$} \\
\hline & & & & Adipose & Liver \\
\hline Riddelliine & 349.4 & 0.2 & 0.710 & 0.15 & 0.67 \\
\hline Riddelliine $\mathrm{N}$-oxide ${ }^{\mathrm{d}}$ & 365.4 & -0.4 & 0.994 & 0.14 & 0.76 \\
\hline Lycopsamine & 299.36 & -0.4 & 0.820 & 0.13 & 0.69 \\
\hline Lycopsamine $\mathrm{N}$-oxide $^{\mathrm{d}}$ & 315.36 & -1 & 0.997 & 0.13 & 0.76 \\
\hline Retrorsine & 351.4 & 0.6 & 0.618 & 0.22 & 0.66 \\
\hline Retrorsine $\mathrm{N}$-oxide ${ }^{\mathrm{d}}$ & 367.4 & 0 & 0.992 & 0.17 & 0.78 \\
\hline Senecionine & 335.4 & 1.1 & 0.491 & 0.42 & 0.70 \\
\hline Senecionine $\mathrm{N}$-oxide ${ }^{\mathrm{d}}$ & 351.4 & 0.5 & 0.987 & 0.27 & 0.82 \\
\hline
\end{tabular}

corresponding PA-N-oxides. The fub is part of the PBK model equation describing glomerular filtration to describe urinary excretion [12]. Hence, at similar total blood concentrations, relatively less PAs will be excreted via glomerular filtration compared to the corresponding PA N-oxides.
In addition to absorption, distribution and excretion, the characteristics of metabolism could also play an important role in defining the toxicity of PAs via, for example, differences in bioactivation and/or metabolic clearance. Bioactivation of PAs to reactive pyrrolic metabolites may occur in the liver, while for PA-N-oxides 


\begin{tabular}{|c|c|c|c|c|c|c|}
\hline Organ/Compound & $\begin{array}{l}\mathrm{V}_{\max }(\mathrm{nmol} / \mathrm{min} / \mathrm{mg} \\
\text { microsomal protein) }\end{array}$ & $\mathrm{K}_{\mathrm{m}}(\mu \mathrm{M})$ & $\begin{array}{l}\text { Catalytic efficiency } \\
\text { (mL/min/mg } \\
\text { microsomal protein) }\end{array}$ & $\begin{array}{l}\text { Scaled } V_{\max } \\
\text { (nmol/min/g } \\
\text { tissue) }^{\mathrm{a}}\end{array}$ & $\begin{array}{l}\text { Scaled catalytic } \\
\text { efficiency } \\
\text { (mL/min/g tissue) }^{a}\end{array}$ & $\begin{array}{l}\text { Scaled catalytic } \\
\text { efficiency } \\
\text { (mL/min/tissue) })^{b}\end{array}$ \\
\hline \multicolumn{7}{|l|}{ Liver } \\
\hline - Lasiocarpine & 5.3 & 19.5 & 0.27 & 186 & 9.5 & 80.9 \\
\hline - Riddelliine & 2.1 & 75.7 & 0.03 & 73.5 & 0.97 & 8.2 \\
\hline - Monocrotaline & 0.06 & 9.2 & 0.01 & 2.1 & 0.2 & 1.9 \\
\hline \multicolumn{7}{|l|}{ Intestine } \\
\hline - Lasiocarpine & 1.7 & 23.4 & 0.07 & 35.0 & 1.50 & 5.2 \\
\hline - Riddelliine & 0.1 & 221 & 0.0005 & 2.06 & 0.009 & 0.03 \\
\hline - Monocrotaline & 0.02 & 13.4 & 0.001 & 0.4 & 0.03 & 0.1 \\
\hline
\end{tabular}

their reduction to the corresponding PA by the intestinal microbiota and in the liver is an important initial step in the bioactivation pathway [13]. When scaled to a whole body, the contribution from gut microbiota to this PA-N-oxide reduction may be higher than that of the liver $[13,14]$. Furthermore, the efficiency of the reduction by the gut microbiota may vary with the PA-N-oxide of interest [14-19].

For the parent PAs, in vitro studies using either microsomal incubations or rat hepatocyte sandwich cultures have revealed substantial variation in metabolic clearance between the examined PAs [20-22]. Based on kinetic data from in vitro liver microsomal incubations, clearance of lasiocarpine was shown to be about 10 -fold more effective than that of riddelliine and 43 -fold more effective than that of monocrotaline ( $\triangleright$ Table 2 ) [22]. These results were in line with data from Lester et al., (2019) [21], who studied the clearance of PAs in rat hepatocyte sandwich cultures and reported the in vitro clearance for these three PAs to also decrease in the order: lasiocarpine > riddelliine > monocrotaline [21]. It is of interest to note that in this latter study the actual relative differences between the clearance rates of the PAs appeared to change with the PA concentration at which the experiments were performed, reflecting differences in the apparent $\mathrm{K}_{\mathrm{m}}$ for this clearance. The observations together raise the question of how such differences in kinetics for clearance should be accounted for when defining relative potency factors for PAs based on in vitro studies.

One could consider using scaling of the in vitro toxicity of the PAs in a specific bioassay using the area under the concentration versus time curve (AUC) obtained in the same experimental model to quantify differences in metabolic clearance. This is what was done by Lester et al. (2019) [21]; these authors divided the level of DNA adduct formation in the hepatocytes by the AUC of the respective PAs in the sandwich rat hepatocyte cultures. The AUC of the parent PA in the culture medium was considered a proxy for PA exposure including clearance, while the ratio of DNA adducts/
AUC was considered a way to characterize relative potency, taking potential differences in clearance into account.

However, the actual clearance rate and the corresponding AUC appeared to vary not only with the PA of interest but also with the PA concentration at which the clearance and AUC were quantified. For example, at 1.0 $\mu \mathrm{M}$ PA the difference in the AUC for riddelliine or lasiocarpine appeared to be substantially larger than the values reported at $100 \mu \mathrm{M}$ PA, an observation that can be ascribed to the relevant $K_{m}$ values ( $\bullet$ Fig. 2 ). This is in line with the relatively less efficient clearance of riddelliine as compared to lasiocarpine observed in incubations with rat liver microsomes with the $\mathrm{K}_{\mathrm{m}}$ for riddelliine clearance being fourfold higher than that of lasiocarpine [20]. Thus, the question emerges as to what AUC to use when scaling the in vitro data to take kinetics characteristics into account. An alternative way to account for such differences in kinetics, including variations in $\mathrm{Km}$ values for clearance among several tested PAs, is using physiologically-based kinetic (PBK) modelling.

\section{Physiologically-based Kinetic (PBK) Modelling}

In physiologically-based kinetic (PBK) modelling, the kinetics of a compound of interest within the body are described by the PBK model. Such PBK models consist of a set of mathematical equations that together describe the ADME characteristics of a compound within an organism [23]. With a PBK model, parameters for different kinetic processes can be integrated in order to predict the physiologically relevant concentrations of a compound in plasma or, when relevant, in the tissue of interest, all for a given dose, time point and route of administration of interest.

In the field of PA toxicity, PBK models have been used for reverse dosimetry based quantitative in vitro to in vivo extrapolation (QIVIVE), translating in vitro data on toxicity or on genotoxicity in primary hepatocytes to predict in vivo acute liver toxicity or in vivo genotoxicity of PAs (for references see $>$ Table 3 ). In this ap- 


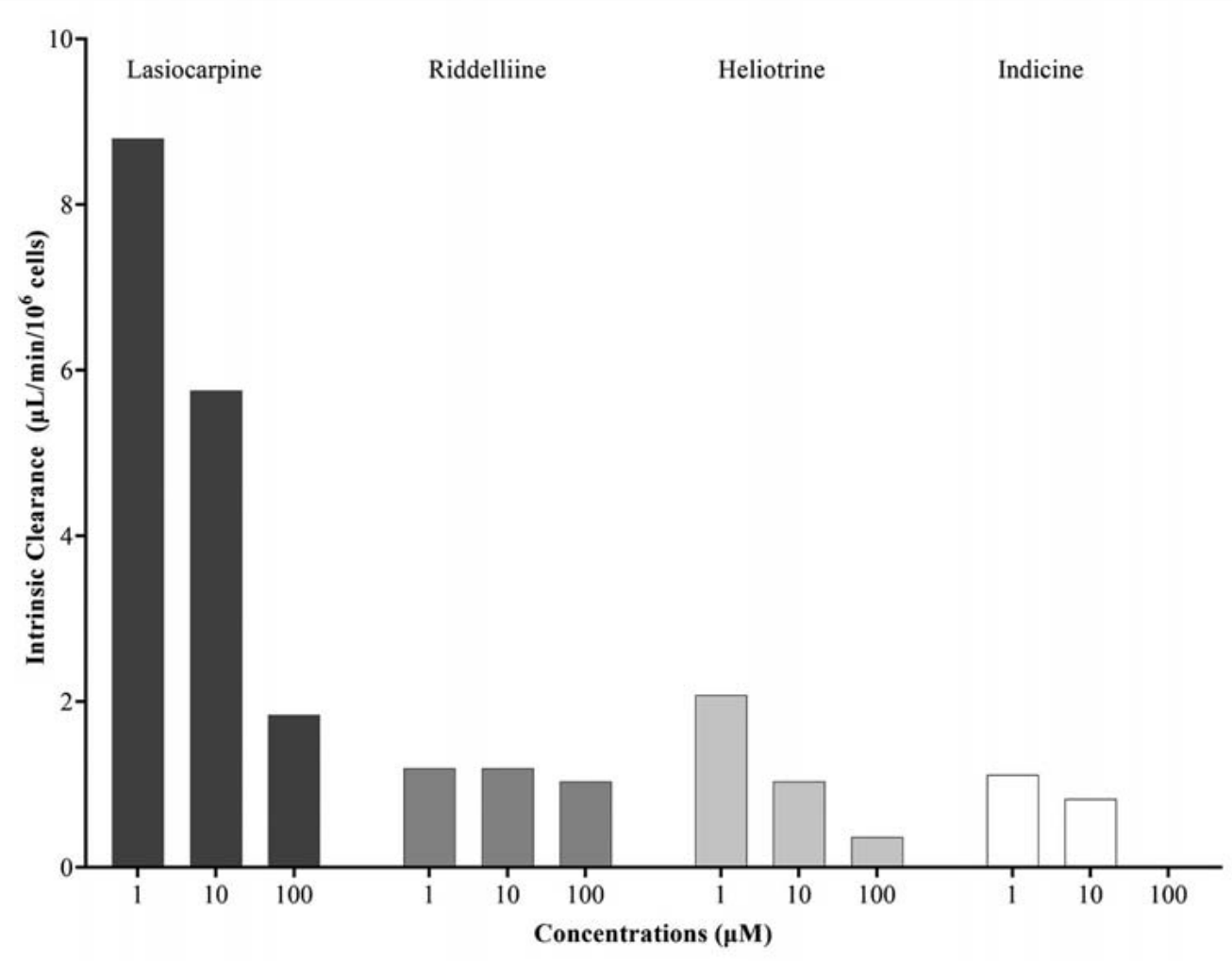

Fig. 2 Clearance of PAs in rat hepatocyte sandwich cultures. Data were extracted from Lester et al. (2019).

proach, the models are used to convert in vitro concentrations to relevant in vivo exposure levels enabling QIVIVE that takes kinetics into account $[24,25]$. In this reverse dosimetry, in vitro concentrations of the concentration-response curve are set equal to plasma or tissue levels of the respective compound in the PBK model. After correcting for potential differences in protein binding, the PBK model can calculate the corresponding in vivo dose level for any given route of administration. Subsequent benchmark dose (BMD) modeling can be applied on the predicted in vivo dose-response data, enabling definition of a point of departure (PoD) for risk assessment, such as a $\mathrm{BMDL}_{\mathrm{x}}$ (the lower confidence limit of the benchmark dose causing an $\mathrm{x} \%$ effect above background level) and BMDUx (the upper confidence limit of the benchmark dose causing an $\mathrm{x} \%$ effect above background level).

PBK modelling has recently been applied to describe the kinetics of three PAs, including riddelliine, lasiocarpine and monocrotaline [20,26-29]. - Fig. $\mathbf{3} \mathbf{a}$ and $\mathbf{b}$ reveal that at a similar oral dose of $10 \mathrm{mg} / \mathrm{kg}$ bw the PBK models predicted substantial differences in both the time-dependent blood concentration and area under the concentration time curve (AUC), respectively, for these three model PAs. - Table 3 presents an overview of studies where the respective PBK models were used for reverse dosimetry to translate in vitro concentration response curves to in vivo dose response curves for either acute liver toxicity or in vivo genotoxicity, from which points of departure (PoDs) were derived.

\section{PBK modelling-based studies on PA toxicity}

Predicting acute liver toxicity

In these PBK studies, in vitro data on the toxicity of the PAs toward primary rat or human hepatocytes were translated to in vivo dose response curves for acute liver toxicity. The predictions for lasiocarpine toxicity in rats could be validated against available in vivo toxicity data. The PBK model based predicted dose response curve for lasiocarpine induced acute liver toxicity resulted in a $\mathrm{BMDL}_{5}$ value of $23.0 \mathrm{mg} / \mathrm{kg} \mathrm{bw} /$ day, which compared well to the in vivo data reported for acute toxicity of lasiocarpine upon a single oral dose amounting to a No Observed Adverse Effect Level (NOAEL) and a Lowest Observed Adverse Effect Level (LOAEL) of 8-80 and $12-120 \mathrm{mg} / \mathrm{kg}$ bw/day, respectively [20,30].

Given that in vivo kinetic data for lasiocarpine are not available, this part of the model evaluation could only be done for riddelliine for which in vivo kinetic data exist $[20,31]$. However, the PBK model and its predictions for lasiocarpine could be evaluated based on comparison of the predicted dose response curve for liver toxicity to available in vivo data for liver toxicity of lasiocarpine $[20,30,32,33]$, whereas this second validation step was not possible for riddelliine for which in vivo liver toxicity data were absent.

- Fig. 4 summarizes the results of the PBK model-based reverse dosimetry as obtained for lasiocarpine as compared to riddelliine [20]. The results demonstrate the importance of taking kinetics into account when considering relative toxic potencies of PAs; the in vitro toxicity of the two PAs in primary rat hepatocytes appeared to indicate that the toxicity of riddelliine and lasiocar- 
- Table 3 Overview of papers reporting PBK models for PAs and predicted points of departure (PoDs) for various PAs by PBK model-based reverse dosimetry of in vitro toxicity data.

\begin{tabular}{|c|c|c|c|c|c|c|}
\hline \multirow[t]{2}{*}{ PAs } & \multirow[t]{2}{*}{ Species } & \multirow[t]{2}{*}{ Ethnic group } & \multirow[t]{2}{*}{ Adverse effect } & \multicolumn{2}{|c|}{ Predicted PoD (mg/kg bw/day) } & \multirow[t]{2}{*}{ Reference } \\
\hline & & & & $\mathrm{BMDL}_{5}$ & $\mathrm{BMD}_{10}$ & \\
\hline \multirow[t]{10}{*}{ Lasiocarpine } & \multirow[t]{2}{*}{ Rat } & \multirow[t]{2}{*}{ n.a. } & Genotoxicity & n.a. & 8.82 & {$[26]$} \\
\hline & & & Acute liver toxicity & 23.0 & 32.5 & [20] \\
\hline & \multirow[t]{8}{*}{ Human } & \multirow[t]{3}{*}{ Caucasian } & Acute liver toxicity & 7.4 & n.a. & [27] \\
\hline & & & & $1.4^{\mathrm{a}}$ & n. a. & [28] \\
\hline & & & & $0.4^{b}$ & n.a. & {$[28]$} \\
\hline & & \multirow[t]{3}{*}{ Chinese } & Acute liver toxicity & 14.7 & n.a. & [27] \\
\hline & & & & $4.4^{\mathrm{a}}$ & n.a. & [28] \\
\hline & & & & $1.8^{\mathrm{b}}$ & n.a. & [28] \\
\hline & & \multirow[t]{2}{*}{ Combined $^{c}$} & Acute liver toxicity & $2.7^{a}$ & n.a. & [28] \\
\hline & & & & $0.8^{\mathrm{b}}$ & n.a. & [28] \\
\hline \multirow[t]{4}{*}{ Riddelliine } & \multirow[t]{2}{*}{ Rat } & \multirow[t]{2}{*}{ n.a. } & Genotoxicity & n.a. & 3.41 & [26] \\
\hline & & & Acute liver toxicity & 4.9 & 2.6 & [20] \\
\hline & \multirow[t]{2}{*}{ Human } & Caucasian & Acute liver toxicity & 0.2 & п. a. & [27] \\
\hline & & Chinese & Acute liver toxicity & 1.0 & n. a. & [27] \\
\hline Monocrotaline & Rat & n.a. & Acute liver toxicity & n.a. & 2.8 & [29] \\
\hline
\end{tabular}
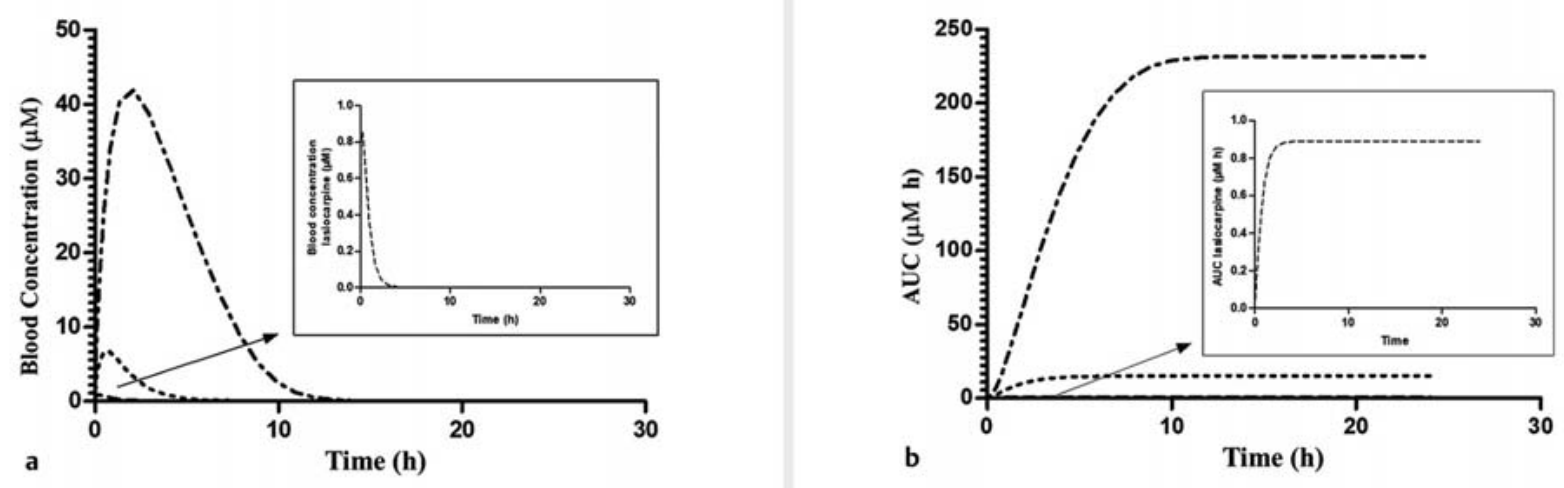

- Fig. 3 PBK model predicted (a) Cmax and (b) AUC of monocrotaline (dashed dotted lines), riddelliine (dotted lines) and lasiocarpine (dashed line in insert) in rats upon an oral dose of $10 \mathrm{mg} / \mathrm{kg}$ bw PA. Data were extracted from the PBK models used previously described by Chen et al. (2018) and Suparmi et al. (2020).

pine is comparable. However, after taking the differences in kinetics into account by PBK model-based translation of the in vitro toxicity data to the in vivo situation, lasiocarpine is predicted to be substantially less toxic than riddelliine. This can be ascribed to the fact that lasiocarpine has faster metabolic clearance; at a similar dose level, lasiocarpine leaves less of the parent PA to be bioactivated and to exert toxicity. The dose level at which riddelliine was predicted to start inducing liver toxicity in rats, reflected by the predicted $\mathrm{BMDL}_{10}-\mathrm{BMDU}_{10}$, amounted to $1.3-3.7 \mathrm{mg} / \mathrm{kg}$ bw/day for riddelliine, a value that matched well with the estimated toxic oral dose range of $1-3 \mathrm{mg} \mathrm{PA} / \mathrm{kg}$ bw/day [34].

A similar study predicted acute liver toxicity in human based on cytotoxicity towards human hepatocytes and reverse dosimetry using human PBK models for lasiocarpine and riddelliine [27]. 


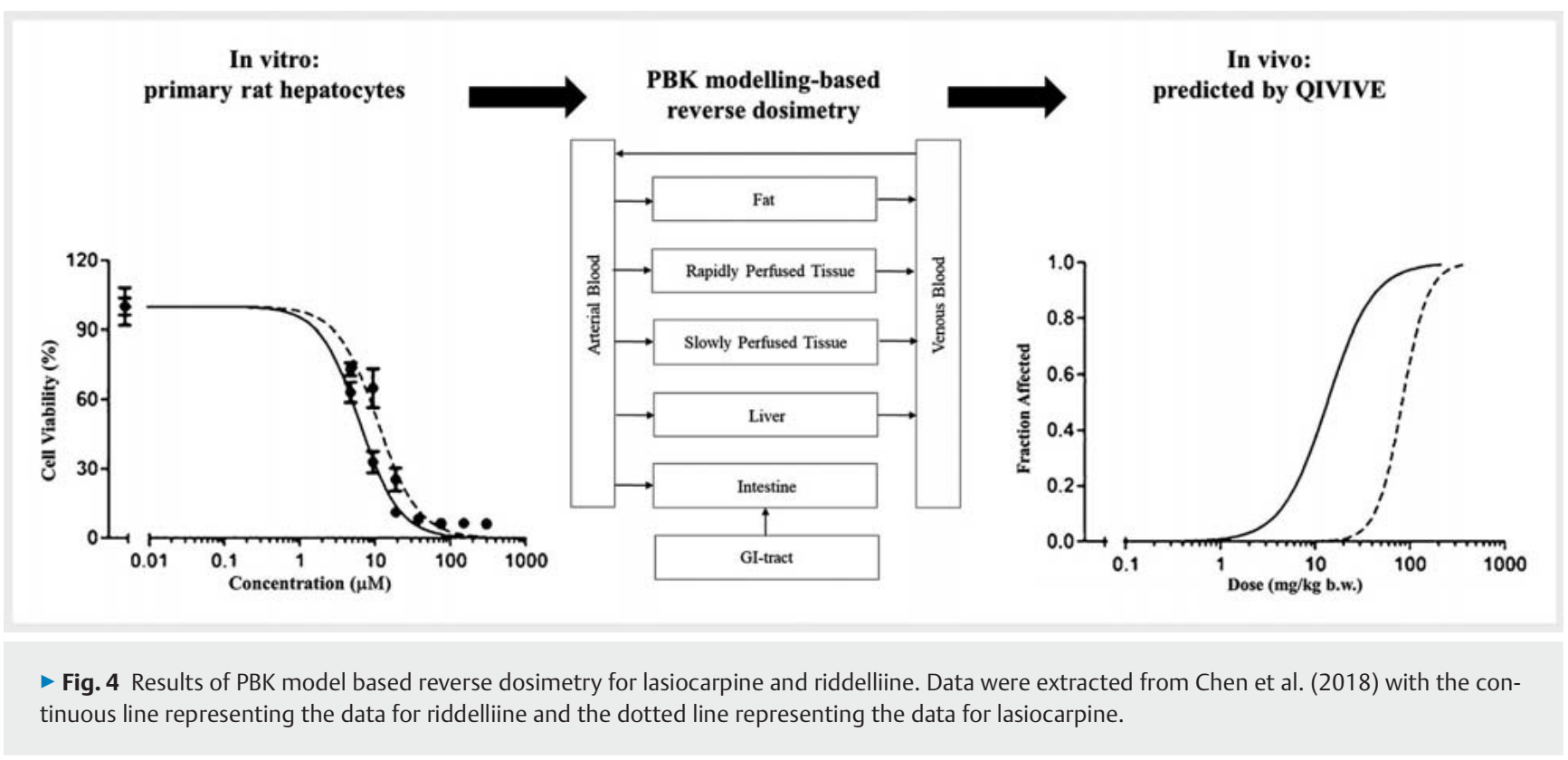

The prediction revealed a similar influence of toxicokinetics, resulting in translation of comparable in vitro concentration response curves to in vivo dose response curves that display differences in toxicity. The predicted in vivo liver toxicity of riddelliine in human was predicted to be 10 - to 28 - fold higher than that of lasiocarpine, again due to the more efficient metabolic clearance of the latter [27]. Although in vitro incubations with human hepatocytes show that riddelliine was 2.1-fold less toxic than lasiocarpine [27], the predicted in vivo difference was the other way around. The predicted in vivo acute liver toxicity of riddelliine and lasiocarpine in human appeared to be even more pronounced than that in rat, with riddelliine being predicted to be 4- to 5- fold more toxic than lasiocarpine for rat and 7- to 10- fold more toxic for human $[20,27,35]$. This result illustrates that differences in kinetics influence relative in vivo potencies of PAs, indicating that in vivo REP values are likely to vary from what would be obtained based on in vitro data alone, and that in vivo REP values may be species dependent.

The data in > Table 3 also illustrate that PBK modelling can be used to study the role of kinetics in the toxicity of PAs for various ethnic groups. Chinese, for example, are predicted to be 2.0 -fold less sensitive towards acute liver toxicity of lasiocarpine and 5.0fold less sensitive towards the acute liver toxicity of riddelliine than Caucasians, due to differences in kinetics. The PBK models revealed that this could be ascribed mainly to less efficient bioactivation of the parent compounds and occurred in spite of less efficient clearance of the PAs in Chinese as compared to Caucasians.

It is also of interest to note that the PBK model-based predictions for in vivo toxicity of PAs reported until now did not refer to toxicity upon repeated dose exposure. In a 28-day study using daily repeated oral exposure to lasiocarpine, a NOAEL for treatmentrelated decrease in body weight gain in male rats of $0.6 \mathrm{mg} / \mathrm{kg}$ bw per day was reported [32]. This is 24- to 43-fold lower than the PoD presented above for acute liver toxicity. Available experimen- tal data and PBK model-based predicted plasma profiles reveal that clearance of the PAs upon an oral dose of $10 \mathrm{mg} / \mathrm{kg}$ bw is expected to be complete within 10 hours $[31,36]$. This suggests that the PA itself would not accumulate upon repeated dosing. However, repeated dosing may result in accumulation of liver damage that may not be repaired within the 24 hours between subsequent doses. This would explain the lower NOAEL values for repeated dose exposure as compared to single exposure regimens. To study this repeated dose toxicity and the potential accumulation of liver damage in in vitro studies, in vitro models other than primary rat hepatocytes will be required to define the toxicity. Various in vitro models with longer incubation times are available, allowing studies on longer exposure duration from 48 hours up to 14 days [37-39].

\section{Predicting genotoxicity}

An important adverse effect of 1,2-unsaturated PAs is their metabolic activation to DNA reactive pyrrole metabolites resulting in a variety of genotoxic effects such as formation of DNA adducts, DNA and protein cross-links, chromosomal aberrations, micronuclei, and DNA double-strand breaks [40-50]. These genotoxic effects are considered to result in gene mutations, leading to tumour formation. Recent efforts have studied the relative potency of a series of PAs and PA-N-oxides in different in vitro assays for DNA damage and/or genotoxicity and defined relative potency $($ REP) values ( $\triangleright$ Table 4$)$.

Allemang et al, (2018) reported the activity of 15 PAs and some PA-N-oxides in the micronucleus assay performed using HepaRG cells, and ranked these compounds in terms of potency based on the BMD confidence intervals ( $\triangleright$ Table 4 ) [40]. Louisse et al. (2019) reported the in vitro concentration-response curves for a series of PAs in human liver HepaRG cells using the phosphorylated histone $\mathrm{H} 2 \mathrm{AX}$ in-cell Western ( $\gamma \mathrm{H} 2 \mathrm{AX} \mathrm{ICW})$ assay [51]. The $\gamma \mathrm{H} 2 \mathrm{AX}$ ICW assay quantifies the amount of phosphorylated histone $\mathrm{H} 2 \mathrm{AX}(\gamma \mathrm{H} 2 \mathrm{AX})$, which is known to represent an unspecific 
- Table 4 REP values of PAs and their $\mathrm{N}$-oxides derived from different models.

\begin{tabular}{|l|l|l|l|l|}
\hline PAs and PA-N-oxides & Merz \& Schrenk (2016) & Louisse et al., (2019) & Allemang et al., (2018) & Lester et al., (2019) \\
\hline & $\begin{array}{l}\text { Combined Cytotoxicity (in vitro), } \\
\text { Genotoxicity in Drosophila and } \\
\text { acute toxicity from rodent } \text { LD }_{\mathbf{5 0}}\end{array}$ & $\begin{array}{l}\text { yH2AX in-cell Western } \\
\text { (ICW) assay, HepaRG cells }\end{array}$ & $\begin{array}{l}\text { Micronucleus assay, } \\
\text { HepaRG cells }\end{array}$ & $\begin{array}{l}\text { DNA adducts/AUC, } \\
\text { rat hepatocytes }\end{array}$ \\
\hline Riddelliine & 1 & 1.00 & 1 & 1 \\
\hline Lasiocarpine & 1 & 1.08 & $5.2-6.3$ & 2.5 \\
\hline Monocrotaline & 1 & 0.06 & $0.023-0.03$ & 0.225 \\
\hline Riddelliine N-oxide & 1 & n.a. & $0.014-0.015$ & n.a. \\
\hline Lasiocarpine N-oxide & 1 & $\leq 0.01$ & $0.008-0.009$ & n.a. \\
\hline Monocrotaline N-oxide & n. a. & n.a. & $0.002-0.003$ & n.a. \\
\hline n. a.: not available & & & & \\
\hline
\end{tabular}

marker of DNA damage $[52,53]$ and has been used as a surrogate endpoint for in vitro genotoxicity [54-57]. They reported PA-N-oxides to be the least potent and two to three orders or magnitude less potent than the corresponding PA, but also recognized that further biokinetics needed to be considered before such data could define robust REP values. A REP value for PA-N-oxides of less than 0.01 , indicated by the results obtained, would not be in line with available in vivo data on DNA adduct formation of PA-N-oxides as compared to their corresponding PAs [45, 47, 58]. This corroborates the need to take in vivo kinetics into account when defining REP values, and that results from in vitro models that do not include possibilities for reduction of PA-N-oxides to their corresponding PA by intestinal microbiota cannot be used to characterize the relative in vivo potency of PA-N-oxides.

Chen et al. (2019) used PBK models for lasiocarpine and riddelliine in rats to convert the in vitro concentration response curves for the activity of these PAs in the $\mathrm{YH} 2 \mathrm{AX}$ assay in primary rat hepatocytes to in vivo dose-response curves [26]. These curves were used to derive PoDs, which were comparable to available in vivo genotoxicity data. This study also revealed that due to the faster metabolic clearance of lasiocarpine than that of riddelliine, the relative potency of lasiocarpine compared to riddelliine is lower in vivo than in vitro [26]. Primary rat hepatocytes were shown to be more sensitive than HepaRG cells in this bioassay. In primary rat hepatocytes, $\mathrm{yH} 2 \mathrm{AX}$ induction was already observed at one to two orders of magnitude lower concentrations, supporting the conclusion that primary hepatocytes provide the preferred model for studies on PA toxicity [26].

\section{Predicting relative potency of PA-N-oxides}

PA-N-oxides constitute an important class of PAs. In botanical preparations, PAs often are encountered in their $\mathrm{N}$-oxide form. Moreover, 8 out of the 17 PAs marked by EFSA as being relevant for monitoring in food and feed were PA-N-oxides [59]. As already outlined above, these PA-N-oxides must first be reduced to their parent PAs to exert toxicity.

Merz and Schrenk (2016) assigned equal interim relative potency (iREP) values for PA-N-oxides to that of the corresponding
PAs ( $\triangleright$ Table 4). This equal treatment of PA-N-oxides and PAs is a worst-case approach. However, results of some in vivo studies reporting DNA adduct formation upon dosing either the PA-N-oxide or a similar dose of the corresponding PA indicate that the REP of PA-N-oxides may be lower than that of their PA analogues $[45,47$, 58]. These results indicate that the REP values of the PA-N-oxides are not equal to those of their parent PAs but are not as low as indicated by results of the various in vitro genotoxicity studies described above.

PBK modelling might provide a better way to define the REP values of PA-N-oxides as compared to their respective PAs. Such models can integrate the kinetics of PA-N-oxide reduction to the parent PA based on results obtained in suitable in vitro models, and can subsequently be used to derive AUC values for systemic exposure to the parent PA upon exposure to the PA itself or to an equimolar dose of the corresponding PA-N-oxide. Comparison of the respective AUC values would provide a novel way to define a REP value for the PA-N-oxides relative to their corresponding PAs.

\section{Consequences of differences in kinetics for toxicity and relative potency factors}

- Table 5 presents an overview of literature data on in vivo kinetic parameters of PAs. - Fig. 5 presents a comparison of the dosenormalized $C_{\max }$ and AUC for different PAs in rats as calculated based on the data presented in $>$ Table 5 . The normalized $C_{\max }$ for adonifoline appears to be 5.5-fold higher than that for riddelliine which is often used as the reference PA, and 6.8-fold higher than that of senecionine $\mathrm{N}$-oxide. The latter may be in part related to the differences in kinetics between PAs and PA N-oxides including the reduction of $\mathrm{N}$-oxides to the parent PAs. When making the comparison on the basis of the dose-normalized AUC, there are also marked distinctions between the examined PAs. In addition, the time dependent concentration curves for the tested PAs show different shapes, illustrating that a high $C_{\max }$ does not automatically imply a high AUC. The ADME characteristics causing these differences remain to be elucidated. Development of PBK models for PAs and PA N-oxides would provide a way to elucidate the underlying reasons causing such kinetic variations. 
- Table 5 In vivo kinetic parameters of PAs as obtained from literature.

\begin{tabular}{|c|c|c|c|c|c|c|c|c|}
\hline \multirow[t]{2}{*}{ PAs } & \multirow[t]{2}{*}{ Species } & \multirow{2}{*}{$\begin{array}{l}\text { Dose } \\
\text { (mg/kg) }\end{array}$} & \multirow[t]{2}{*}{ Administration } & \multicolumn{4}{|c|}{ Kinetic parameters } & \multirow[t]{2}{*}{ References } \\
\hline & & & & $\begin{array}{l}C_{\max } \\
(\mu g / m L)\end{array}$ & $\begin{array}{l}\text { AUC }(0-t) \\
(\mu \mathrm{g} \mathrm{min} / \mathrm{mL})\end{array}$ & $\begin{array}{l}\operatorname{AUC}(0-\infty) \\
(\mu \mathrm{g} \min / \mathrm{mL})\end{array}$ & $\begin{array}{l}\text { Tmax } \\
(\min )\end{array}$ & \\
\hline \multirow[t]{7}{*}{ Indicine $\mathrm{N}$-oxide } & \multirow[t]{4}{*}{ Human } & 12.16 & \multirow[t]{4}{*}{ Intravenous } & 25 & n.a. & n.a. & n.a. & \multirow[t]{4}{*}[74]{} \\
\hline & & 27.02 & & 60 & n.a. & n.a. & n.a. & \\
\hline & & 40.54 & & 100 & n.a. & n.a. & n.a. & \\
\hline & & 81.08 & & 400 & n.a. & n.a. & n.a. & \\
\hline & \multirow[t]{3}{*}{ Rabbit } & 25 & \multirow[t]{3}{*}{ Intravenous } & 40 & n.a. & n.a. & n. a. & \multirow[t]{3}{*}[16]{} \\
\hline & & 56 & & 100 & n.a. & n.a. & n.a. & \\
\hline & & 111 & & 200 & n.a. & n.a. & n.a. & \\
\hline \multirow[t]{2}{*}{ Riddelliine } & $\begin{array}{l}\text { Rat Male } \\
\text { Female }\end{array}$ & 10 & Oral & $\begin{array}{l}0.25 \\
0.4\end{array}$ & $\begin{array}{l}\text { n.a. } \\
\text { n.a. }\end{array}$ & $\begin{array}{l}30.96 \\
76.02\end{array}$ & $\begin{array}{l}\text { n.a. } \\
\text { n.a. }\end{array}$ & \multirow[t]{2}{*}{ [31] } \\
\hline & $\begin{array}{l}\text { Mice Male } \\
\text { Female }\end{array}$ & 10 & Oral & $\begin{array}{l}1.3 \\
1.25\end{array}$ & $\begin{array}{l}\text { n.a. } \\
\text { n.a. }\end{array}$ & $\begin{array}{l}78.42 \\
63.84\end{array}$ & $\begin{array}{l}\text { n.a. } \\
\text { n.a. }\end{array}$ & \\
\hline Riddelliine $\mathrm{N}$-oxide & Rat & 20 & Oral & 0.5481 & 1278.9 & n.a. & 120 & {$[14]$} \\
\hline \multirow[t]{5}{*}{ Senecionine } & \multirow[t]{5}{*}{ Rat } & 1.5 & Intravenous & 9.83 & n. a. & 72.12 & 2.00 & {$[75,76]$} \\
\hline & & 5.7 & \multirow[t]{4}{*}{ Oral } & 0.48 & 29.74 & 30.13 & 22.22 & \multirow[t]{2}{*}[76]{} \\
\hline & & 11.5 & & 0.49 & 32.97 & 33.14 & 15.56 & \\
\hline & & 18.445 & & 0.20579 & 17.24 & n.a. & 10.00 & {$[36]$} \\
\hline & & 22.9 & & 1.27 & 76.30 & 76.72 & 21.11 & {$[76]$} \\
\hline Senecionine $\mathrm{N}$-oxide & Rat & 19.33 & Oral & 0.392 & 118.82 & n.a. & 213.33 & [36] \\
\hline \multirow[t]{4}{*}{ Adonifoline } & \multirow[t]{4}{*}{ Rat } & 4.0 & Intravenous & 40.3 & 320.2 & 334.03 & 2.00 & {$[75,76]$} \\
\hline & & 16 & Oral & 1.5 & 364 & 373.7 & 69.3 & \multirow[t]{3}{*}[76]{} \\
\hline & & 32 & & 4.4 & 804.2 & 814.9 & 52.8 & \\
\hline & & 64 & & 9.8 & 2296.6 & 2367.6 & 62.2 & \\
\hline \multirow[t]{4}{*}{ Seneciphylline } & \multirow[t]{4}{*}{ Rat } & 2 & Intravenous & n.a. & 101.41 & 106.32 & n.a. & \multirow[t]{4}{*}[77]{} \\
\hline & & 10 & \multirow[t]{3}{*}{ Intragastric } & 0.82 & 57.45 & 58.24 & 18.6 & \\
\hline & & 20 & & 1.37 & 79.61 & 81.83 & 13.8 & \\
\hline & & 40 & & 1.75 & 109.04 & 112.52 & 19.2 & \\
\hline \multirow[t]{3}{*}{ Monocrotaline } & Rat & 60 & Intravenous & 36.765 & n.a. & n.a. & n.a. & {$[29,78]$} \\
\hline & \multirow[t]{2}{*}{ Mice } & 3 & Intravenous & 2.5538 & 179.51 & 193.55 & n.a. & \multirow[t]{2}{*}{ [79] } \\
\hline & & 15 & Oral & 9.8865 & 792.9 & 795.58 & 30 & \\
\hline
\end{tabular}

n. a.: not available

Several studies already defined REP values for PAs based on in vitro testing strategies. Merz and Schrenk (2016), for example, defined interim relative potency factors (iREP) based on available literature data on in vitro cytotoxicity, in combination with genotoxicity data obtained in Drosophila, and acute toxicity data from rodent studies $\left(L_{50}\right)$ [60]. Allemang et al. (2018) defined REP values based on the potency of a series of 15 PAs, including some $\mathrm{PA}-\mathrm{N}$-oxides, in the micronucleus (MN) assay performed in HepaRG cells [40]. Louisse et al. (2019) also used HepaRG cells to define REP values using $\mathrm{YH} 2 \mathrm{AX}$ induction as the read out [51].
- Table 4 provides an overview of the REP values defined in previous studies for the model compounds used in our PBK-based studies until now. As already discussed, using these in vitro assays to define REP values for PA-N-oxides is hampered by the fact that the in vitro models do not contain the system for metabolic reduction of the PA-N-oxides to the corresponding PAs. The REP values of 1.00 listed by Merz and Schrenk (2016) were based on the worst-case assumption that all PA-N-oxides would be efficiently converted to the corresponding PA [60].

The REP values derived for riddelliine, lasiocarpine and monocrotaline based on data from in vitro studies may also be affected 


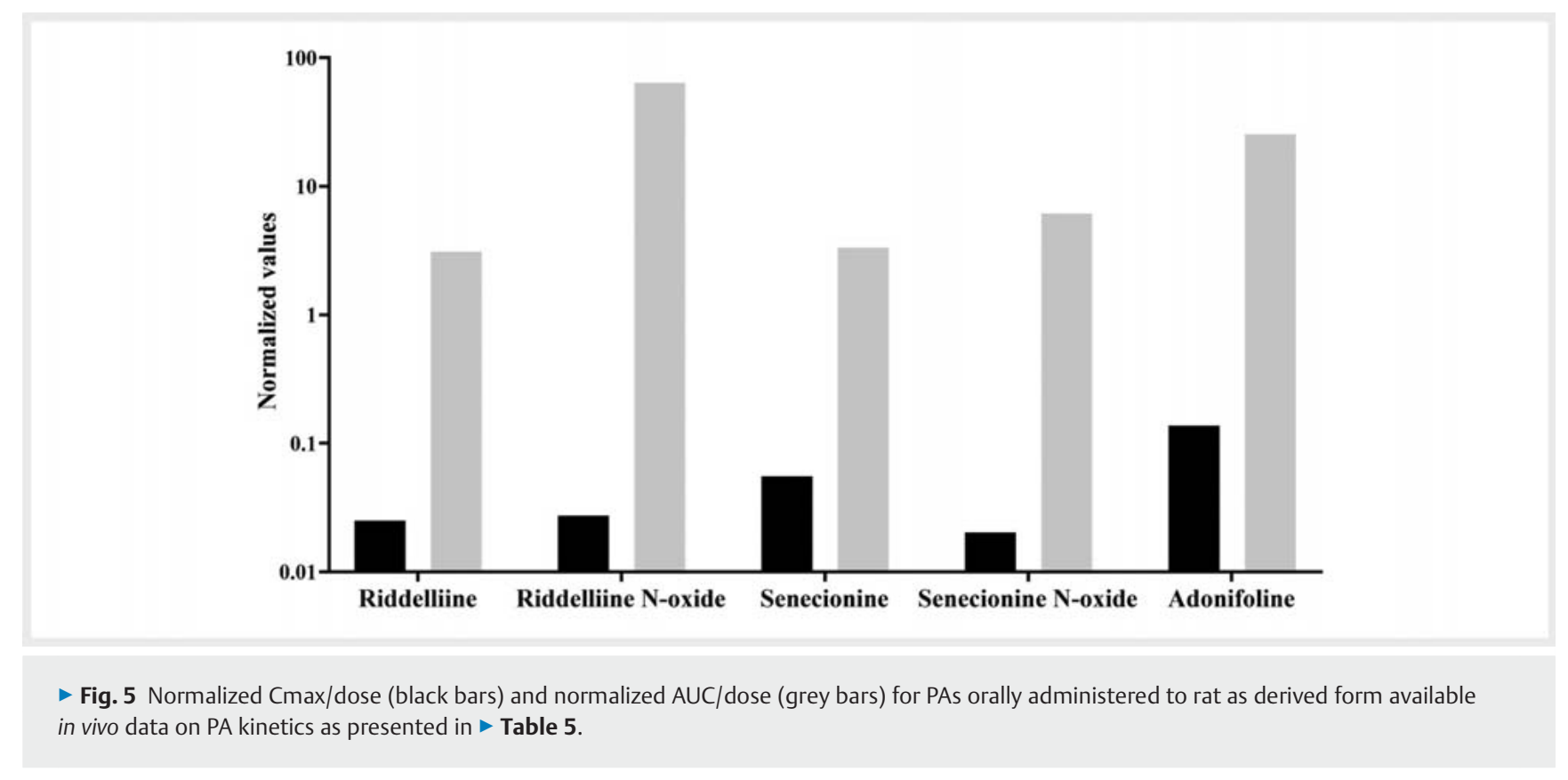

by the fact that the in vitro models do not take differences in kinetics into account. Lester et al. (2019) [21] acknowledged this aspect by defining the REP values based on DNA adduct levels formed in exposed rat hepatocytes divided by the AUC of the respective PA in the hepatocyte incubation medium to account for differences in clearance efficiency. The study by Chen et al. (2019) reveals that use of the in vitro-PBK modelling-based approach for predicting in vivo genotoxicity results in a REP value of lasiocarpine relative to riddelliine amounting to 2.6 , being the ratio between the $\mathrm{BMD}_{10}$ values derived from the predicted in vivo dose response curves [26]. This value is comparable to the value of 2.5 derived by Lester et al. (2019) [21], who also included a correction for differences in clearance, while both these values are lower than the value of 5.2-6.3 derived from the MN assay without considering the characteristics of clearance [21]. A lower REP value for lasiocarpine relative to riddelliine, upon taking kinetics into account, may be related to more efficient clearance of lasiocarpine than that of riddelliine. The about $2-2.5$-fold higher in vivo genotoxic potency of lasiocarpine than of riddelliine is also in line with the difference in their $\mathrm{BMDL}_{10}$ values derived from data on the incidence of liver hemangiosarcoma obtained in 2-year carcinogenicity studies in rats upon chronic oral exposure to lasiocarpine and riddelliine $[61,62]$. EFSA derived a $\mathrm{BMD}_{10}$ of $0.131 \mathrm{mg} /$ $\mathrm{kg}$ bw/day for lasiocarpine and of $0.292 \mathrm{mg} / \mathrm{kg}$ bw/day for riddelliine [1]. These values also indicate that the relative potencies for in vivo acute liver toxicity (with riddelliine being most potent), vary from the values derived from in vivo genotoxicity and carcinogenicity (with lasiocarpine being most potent).

\section{Discussion}

The overview presented in the present paper illustrates that kinetics is a key determinant in PA or PA-N-oxide toxicity, and that definition of REP values should take differences in in vivo kinetics into account. Including kinetics when defining REP values can be done by using in vivo data to define the REP values. However, only for a limited number of the 1,2-unsaturated PAs and their N-oxides in vivo toxicity data are available. This data limitation combined with ethical constraints and the fact that data obtained in experimental animals may not reflect the human situation, indicate a need for new approach methodologies (NAMs) that apply alternative testing strategies.

When considering the use of in vitro-based NAMs to define in vivo relative potencies it appears important to take differences in kinetics into account. The use of clearance data for this consideration, quantifying the disappearance of the parent PA in the respective in vitro incubations, may not give the most adequate parameter to reflect the variations in kinetics. Clearance will include both bioactivation and detoxification. An example that illustrates this can be found in the comparison of the acute liver toxicity predicted for the Caucasian and Chinese populations. The Chinese are predicted to be less sensitive because of differences in kinetics, despite higher $C_{\max }$ values for the PAs due to slower clearance. This is because at the same time the Chinese show relatively lower catalytic efficiency for bioactivation of the PAs [27]. Using PBK model-based reverse dosimetry of data obtained in an in vitro model can reflect the consequences of such differences for the in vivo toxicity since it converts the in vitro toxic concentration of the PA to a corresponding in vivo dose level taking all kinetics into account. For such PBK models the kinetics for both bioactivation and detoxification could be characterized in vitro by using glutathione as a scavenger for the reactive pyrrole intermediate. The rate of clearance minus the rate of bioactivation allows quantification of the rate of detoxification.

It is also relevant to point out that the type of endpoint may be another reason causing the variations in the REP values. The induction of micronuclei, for example, reflects chromosome damaging potential in cells that have undergone cell division [63]. 


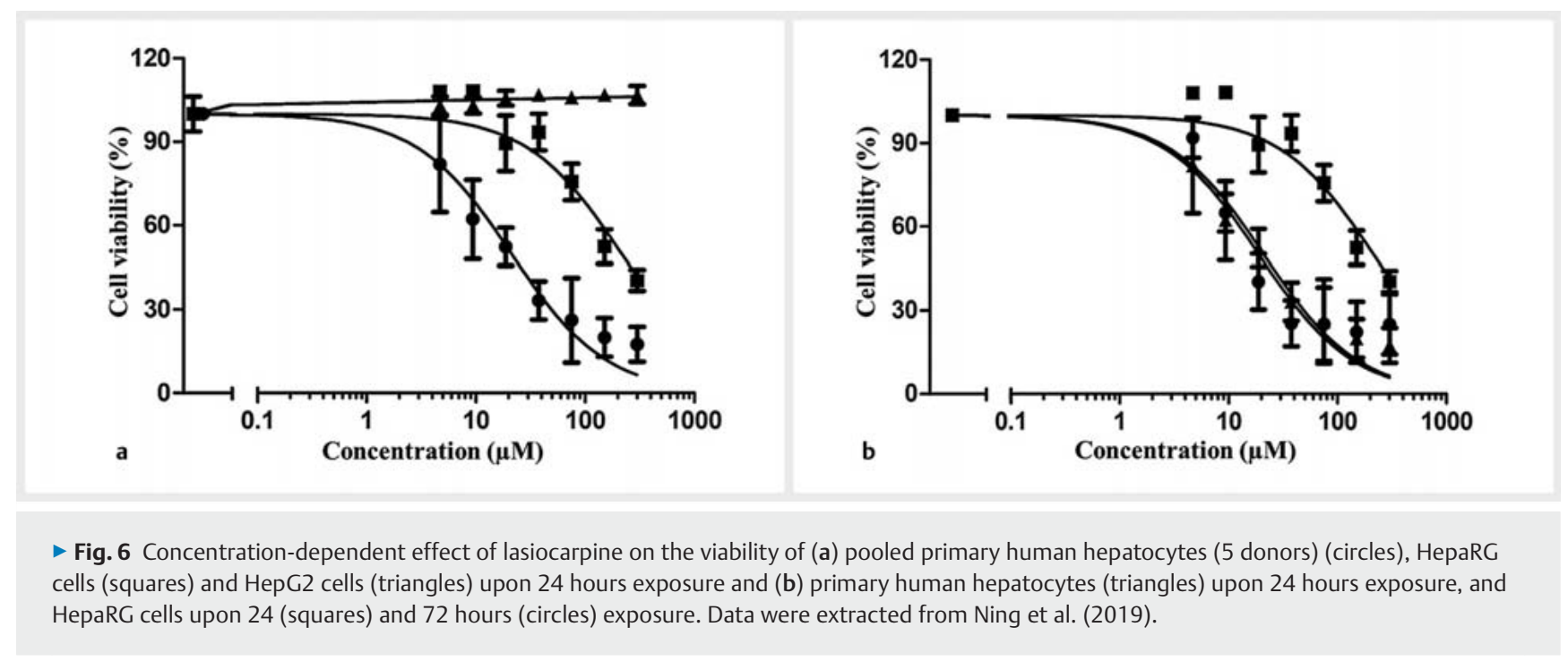

The phosphorylation of histone H2AX can be caused by DNA double strand breaks $[64,65]$, while $\mathrm{yH} 2 \mathrm{AX}$ can also be induced by other cellular processes and may not always reflect direct DNA damage and genotoxicity $[52,56,66]$. $\gamma \mathrm{H} 2 \mathrm{AX}$ can be a consequence of apoptosis rather than reflecting true genotoxicity [67, 68].

Given that kinetics and bioactivation play an essential role in the ultimate toxicity, the in vitro cell model used to study toxicity or genotoxicity of PAs may influence the results obtained. Using lasiocarpine as the model PA, this is illustrated by the results presented in $\triangleright$ Fig. $\mathbf{6}$, showing the concentration dependent effect of lasiocarpine on the viability of pooled primary human hepatocytes, HepaRG cells and HepG2 cells. HepaRG cells are considered to have a similar biotransformation capacity as primary hepatocytes, also having high expression of CYP3A4, the key enzyme for PA metabolism in human [69-71]. The results presented in - Fig. 6 a reveal that lasiocarpine appeared to be not toxic toward HepG2 cells at the concentrations tested, likely due to the lack of sufficient CYP activity. The results also reveal that lasiocarpine was more toxic in pooled primary human hepatocytes than in HepaRG cells. However, when for the HepaRG cells exposure duration was extended from 24 to 72 hours the effect of lasiocarpine on the viability of the cells appeared comparable to what was observed for the pooled human primary hepatocytes upon $24 \mathrm{~h}$ exposure ( $\bullet$ Fig. 6b). When considering the use of an in vitro cell model it is also of importance to note that freshly isolated primary human hepatocytes may show substantial variation in terms of CYP3A4 activity pointing at the need to use pooled batches of human primary hepatocytes to eliminate interindividual variability in kinetics as much as possible. Furthermore, it has also been reported that HepaRG 3D spheroids have greater CYP 3A4 activity, than the HepaRG cultured in 2D monolayers [72].

Previous studies pointed at a lower sensitivity of HepaRG cells than of primary hepatocytes towards the toxicity of PAs. The IC $\mathrm{C}_{50}$ value of lasiocarpine for effects on cell viability in the primary rat hepatocytes was 2- and 20-fold lower than the values for the primary human hepatocytes and HepaRG cells, respectively; while the $\mathrm{IC}_{50}$ value of riddelliine in the primary rat hepatocytes was 7-fold and 22-fold lower than the values for the primary human hepatocytes and HepaRG cells, respectively [20,27]. Quantifying $\mathrm{yH} 2 \mathrm{AX}$ formation as the endpoint for genotoxicity, the primary rat hepatocytes appeared to be about one to two orders of magnitude more sensitive to lasiocarpine and riddelliine induced genotoxicity than the HepaRG cells, with in these respective models lasiocarpine being 1.1 fold and 3.5 fold more potent than riddelliine [26].

It is worthwhile to consider re-investigating the derived relative potency values from such assays using other cell models. Comparing the BMD confidence interval values with lower and upper confidence limits (CEDL and CEDU respectively) reported by Allemang et al. (2018) for lasiocarpine and riddelliine in HepaRG cells using the micronucleus assay $(0.8-1.1 \mu \mathrm{M}$ and $4.3-6.9 \mu \mathrm{M}$ respectively) [40], and the $\mathrm{BMC}_{50}$ values for lasiocarpine and riddelliine derived from the $\gamma \mathrm{H} 2 \mathrm{AX}$ concentration-response curves $(5.3 \mu \mathrm{M}$ and $5.8 \mu \mathrm{M}$ respectively) [51], and the $\mathrm{BMC}_{10}$ values obtained when the $\mathrm{\gamma H} 2 \mathrm{AX}$ assay is performed in rat hepatocytes $(2.09 \mu \mathrm{M}$ and $2.17 \mu \mathrm{M})[26]$ reveals that in the same cell model, the micronucleus endpoint is 6.6- and 1.3-fold more sensitive for lasiocarpine and riddelliine, respectively, than the $\gamma \mathrm{H} 2 \mathrm{AX}$ endpoint. When comparing the same $\mathrm{yH} 2 \mathrm{AX}$ endpoint in different cell models, it appears that rat hepatocytes are 105- and 31- fold more sensitive toward lasiocarpine and riddelliine, respectively, than the HepaRG cells [26]. This may be due to a relatively higher level of bioactivation in primary hepatocytes than in HepaRG cells as observed for human hepatocytes ( $\bullet$ Fig. $\mathbf{6 a}$ ) and/or to species dependent differences. Altogether these examples indicate that the REP values may vary with the endpoint and in vitro cell model used, with the latter at least in part being likely due to variations in the metabolic characteristics of the employed cell models.

Ideally, an in vitro model to quantify PA liver toxicity should most closely resemble the human situation. Use of human primary hepatocytes would then be of value but they also come with limitations, such as donor-to-donor variability. Thus, at the current state-of-the art it seems best to use pooled human hepato- 
cytes. Alternatively, human hepatocytes derived from iPSCs generated from multiple individuals with different polymorphic characteristics may provide a supply of hepatocytes for highthroughput screening with minor batch-to-batch variability to improve reproducibility [73]. Whatever in vivo model and endpoint applied, results obtained in an in vitro model need further translation to the in vivo situation, for example, by using PBK model based reverse dosimetry to also account for differences in in vivo kinetics between the examined PAs.

Taking it all together, it is concluded that the use of NAMs is important to fill the data gaps that currently exist for PAs relevant in food and feed. Whatever the alternative testing strategy applied, it is important to consider that the relative toxicity of PAs will depend on both toxicokinetics and toxicodynamics. While in vitro toxicity tests may reveal differences in relative potencies and thus in toxicodynamics, the role of toxicokinetics in PA induced toxicity should not be ignored.

\section{Supporting Information}

Electronic supplementary information is available for this publication, where the reader can find an overview of keywords used for the literature search strategy.

\section{Contributors' Statement}

Conception and design of the work: I.M.C.M. Rietjens; drafting the manuscript: I. M. C. M. Rietjens, F. Widjaja, Y. Alhejji; critical revision of the manuscript: I. M. C. M. Rietjens, F. Widjaja, Y. Alhejji; data collection: F. Widjaja, Y. Alhejji; analysis and interpretation of the data: I. M. C. M. Rietjens, F. Widjaja, Y. Alhejji.

\section{Acknowledgements}

Yasser Alhejji received a scholarship for his PhD studies at Wageningen University from Qassim University with grant number 35796.

\section{Conflict of Interest}

The authors declare that they have no conflict of interest.

\section{References}

[1] EFSA Scientific Committee, Hardy A, Benford D, Halldorsson T, Jeger M], Knutsen KH, More S, Mortensen A, Naegeli H, Noteborn H, Ockleford C, Ricci A, Rychen G, Silano V, Solecki R, Turck D, Aerts M, Bodin L, Davis A, Edler L, Gundert-Remy U, Sand S, Slob W, Bottex B, Abrahantes JC, Marques DC, Kass G, Schlatter JR. Update: Use of the benchmark dose approach in risk assessment. EFSA J 2017; 15: e04658

[2] Yang M, Ma J, Ruan J, Zhang C, Ye Y, Fu PPC, Lin G. Absorption difference between hepatotoxic pyrrolizidine alkaloids and their N-oxides-Mechanism and its potential toxic impact. J Ethnopharmacol 2020; 249: 112421

[3] Tu M, Sun S, Wang K, Peng X, Wang R, Li L, Zeng S, Zhou H, Jiang H. Organic cation transporter 1 mediates the uptake of monocrotaline and plays an important role in its hepatotoxicity. Toxicology 2013; $311: 225-$ 230

[4] Koepsell H, Endou H. The SLC22 drug transporter family. Pflügers Archiv 2004; 447: 666-676
[5] Tu M, Li L, Lei H, Ma Z, Chen Z, Sun S, Xu S, Zhou H, Zeng S, Jiang H. Involvement of organic cation transporter 1 and CYP3A4 in retrorsine-induced toxicity. Toxicology 2014; 322: 34-42

[6] Evans DF, Pye G, Bramley R, Clark AG, Dyson TJ, Hardcastle JD. Measurement of gastrointestinal $\mathrm{pH}$ profiles in normal ambulant human subjects. Gut 1988; 29: 1035-1041

[7] McConnell EL, Basit AW, Murdan S. Measurements of rat and mouse gastrointestinal $\mathrm{pH}$, fluid and lymphoid tissue, and implications for in-vivo experiments. J Pharm Pharmacol 2008; 60: 63-70

[8] Berezhkovskiy LM. Volume of distribution at steady state for a linear pharmacokinetic system with peripheral elimination. J Pharm Sci 2004; 93: $1628-1640$

[9] Punt A, Pinckaers N, Peijnenburg A, Louisse J. Development of a webbased toolbox to support Quantitative In-Vitro-to-In-Vivo Extrapolations (QIVIVE) within nonanimal testing strategies. Chem Res Toxicol 2020; 34: $460-472$

[10] Lobell M, Sivarajah V. In silico prediction of aqueous solubility, human plasma protein binding and volume of distribution of compounds from calculated pK a and AlogP98 values. Mol Divers 2003; 7: 69-87

[11] Gao Y, Gesenberg C, Zheng W. Oral Formulations for preclinical Studies: Principle, Design, and Development Considerations. In: Qiu Y, Chen Y, Zhang GGZ, Yu L, Mantri RV, eds. Developing solid oral Dosage Forms. Amsterdam: Elsevier; 2017: 455-495

[12] Noorlander A, Wesseling S, Rietjens IMCM, van Ravenzwaay B. Incorporating renal excretion via the OCT2 transporter in physiologically based kinetic modelling to predict in vivo kinetics of mepiquat in rat. Toxicol Lett 2021; 343: 34-43

[13] Mattocks A. Chemistry and Toxicology of Pyrrolizidine Alkaloids. London: Academic Press; 1986

[14] Yang M, Ma J, Ruan J, Ye Y, Fu PPC, Lin G. Intestinal and hepatic biotransformation of pyrrolizidine alkaloid $\mathrm{N}$-oxides to toxic pyrrolizidine alkaloids. Arch Toxicol 2019; 93: 2197-2209

[15] Mattocks AR. Hepatotoxic effects due to pyrrolizidine alkaloid N-oxides. Xenobiotica 1971; 1: 563-565

[16] Powis G, Ames MM, Kovach JS. Metabolic conversion of indicine N-oxide to indicine in rabbits and humans. Cancer Res 1979; 39: 3564-3570

[17] Chu PS, Lamé MW, Segall H. In vivo metabolism of retrorsine and retrorsine-N-oxide. Arch Toxicol 1993; 67: 39-43

[18] Jago MV, Edgar J, Smith L, Culvenor C. Metabolic conversion of heliotridine-based pyrrolizidine alkaloids to dehydroheliotridine. Mol Pharmacol 1970; 6: 402-406

[19] Phillipson J, Handa S. Alkaloid N-oxides. A review of recent developments. Lloydia 1978; 41: 385-431

[20] Chen L, Ning J, Louisse J, Wesseling S, Rietjens IM. Use of physiologically based kinetic modelling-facilitated reverse dosimetry to convert in vitro cytotoxicity data to predicted in vivo liver toxicity of lasiocarpine and riddelliine in rat. Food Chem Toxicol 2018; 116: 216-226

[21] Lester C, Troutman J, Obringer C, Wehmeyer K, Stoffolano P, Karb M, Xu Y, Roe A, Carr G, Blackburn K. Intrinsic relative potency of a series of pyrrolizidine alkaloids characterized by rate and extent of metabolism. Food Chem Toxicol 2019; 131: 110523

[22] Suparmi S, Wesseling S, Rietjens IMCM. Monocrotaline-induced liver toxicity in rat predicted by a combined in vitro physiologically based kinetic modeling approach. Arch Toxicol 2020; 94: 3281-3295

[23] Rietjens IMCM, Louisse ], Punt A. Tutorial on physiologically based kinetic modeling in molecular nutrition and food research. Molecular Nutr \& Food Res 2011; 55: 941-956

[24] Louisse J, Beekmann K, Rietjens IMCM. Use of physiologically based kinetic modeling-based reverse dosimetry to predict in vivo toxicity from in vitro data. Chem Res Toxicol 2017; 30: 114-125 
[25] Louisse ], Verwei M, Woutersen RA, Blaauboer B], Rietjens IMCM. Toward in vitro biomarkers for developmental toxicity and their extrapolation to the in vivo situation. Expert Opin Drug Metab Toxicol 2012; 8: 11-27

[26] Chen L, Peijnenburg A, de Haan L, Rietjens IMCM. Prediction of in vivo genotoxicity of lasiocarpine and riddelliine in rat liver using a combined in vitro-physiologically based kinetic modelling-facilitated reverse dosimetry approach. Arch Toxicol 2019; 93: 2385-2395

[27] Ning J, Chen L, Strikwold M, Louisse J, Wesseling S, Rietjens IMCM. Use of an in vitro-in silico testing strategy to predict inter-species and inter-ethnic human differences in liver toxicity of the pyrrolizidine alkaloids lasiocarpine and riddelliine. Arch Toxicol 2019; 93: 801-818

[28] Ning J, Rietjens IMCM, Strikwold M. Integrating physiologically based kinetic (PBK) and Monte Carlo modelling to predict inter-individual and inter-ethnic variation in bioactivation and liver toxicity of lasiocarpine. Arch Toxicol 2019; 93: 2943-2960

[29] Suparmi S, Wesseling S, Rietjens IMCM. Monocrotaline-induced liver toxicity in rat predicted by a combined in vitro physiologically based kinetic modeling approach. Arch Toxicol 2020; 94: 3281

[30] Nolan JP, Scheig RL, Klatskin G. Delayed hepatitis and cirrhosis in weanling rats following a single small dose of the senecio alkaloid, lasiocarpine. Am J Pathol 1966; 49: 129

[31] Williams L, Chou MW, Yan J, Young JF, Chan PC, Doerge DR. Toxicokinetics of riddelliine, a carcinogenic pyrrolizidine alkaloid, and metabolites in rats and mice. Toxicol Appl Pharmacol 2002; 182: 98-104

[32] Dalefield RR, Gosse MA, Mueller U. A 28-day oral toxicity study of echimidine and lasiocarpine in Wistar rats. Regul Toxicol Pharmacol 2016; 81: $146-154$

[33] Jago MV. A method for the assessment of the chronic hepatoxicity of pyrrolizidine alkaloids. Aust JI Exp Biol Med Sci 1970; 48: 93-103

[34] EFSA Panel on Contaminants in the Food Chain (CONTAM), Knutsen HK, Alexander J, Barregård L, Bignami M, Brüschweiler B, Ceccatelli S, Cottrill B, Dinovi M, Edler L, Grasl-Kraupp B, Hogstrand C, Hoogenboom LR, Nebbia CS, Oswald IP, Petersen A, Rose M, Roudot AC, Schwerdtle T, Vleminckx C, Vollmer G, Wallace H, Gomez Ruiz JA, Binaglia M. Risks for human health related to the presence of pyrrolizidine alkaloids in honey, tea, herbal infusions and food supplements. EFSA J 2017; 15: e04908

[35] Schrenk D, Gao L, Lin G, Mahony C, Mulder PP, Peijnenburg A, Pfuhler S, Rietjens IM, Rutz L, Steinhoff B. Pyrrolizidine alkaloids in food and phytomedicine: Occurrence, exposure, toxicity, mechanisms, and risk assessment-A review. Food Chem Toxicol 2020; 136: 111107

[36] Yang M, Ruan J, Gao H, Li N, Ma J, Xue J, Ye Y, Fu PP, Wang J, Lin G. First evidence of pyrrolizidine alkaloid $\mathrm{N}$-oxide-induced hepatic sinusoidal obstruction syndrome in humans. Arch Toxicol 2017; 91: 3913-3925

[37] Waizenegger J, Braeuning A, Templin M, Lampen A, Hessel-Pras S. Structure-dependent induction of apoptosis by hepatotoxic pyrrolizidine alkaloids in the human hepatoma cell line HepaRG: Single versus repeated exposure. Food Chem Toxicol 2018; 114: 215-226

[38] Xiong F, Jiang K, Chen Y, Ju Z, Yang L, Xiong A, Wang Z. Protein crosslinking in primary cultured mouse hepatocytes by dehydropyrrolizidine alkaloids: Structure-toxicity relationship. Toxicon 2020; 186: 4-11

[39] Gao L, Rutz L, Schrenk D. Structure-dependent hepato-cytotoxic potencies of selected pyrrolizidine alkaloids in primary rat hepatocyte culture. Food Chem Toxicol 2020; 135: 110923

[40] Allemang A, Mahony C, Lester C, Pfuhler S. Relative potency of fifteen pyrrolizidine alkaloids to induce DNA damage as measured by micronucleus induction in HepaRG human liver cells. Food Chem Toxicol 2018; 121: 72-81

[41] Chou MW, Jian Y, Williams LD, Xia Q, Churchwell M, Doerge DR, Fu PP. Identification of DNA adducts derived from riddelliine, a carcinogenic pyrrolizidine alkaloid. Chem Res Toxicol 2003; 16: 1130-1137

[42] Chou MW, Yan J, Nichols J, Xia Q, Beland FA, Chan PC, Fu PP. Correlation of DNA adduct formation and riddelliine-induced liver tumorigenesis in
F344 rats and B6C3F1 mice [Cancer Lett. 193 (2003) 119-125]. Cancer Lett 2004; 207: 119-125

[43] Fu PP, Chou MW, Churchwell M, Wang Y, Zhao Y, Xia Q, Gamboa da Costa G, Marques MM, Beland FA, Doerge DR. High-performance liquid chromatography electrospray ionization tandem mass spectrometry for the detection and quantitation of pyrrolizidine alkaloid-derived DNA adducts in vitro and in vivo. Chem Res Toxicol 2010; 23: 637-652

[44] Fu PP, Xia Q, Lin G, Chou MW. Pyrrolizidine alkaloids-genotoxicity, metabolism enzymes, metabolic activation, and mechanisms. Drug Metab Rev 2004; 36: 1-55

[45] Wang YP, Yan J, Fu PP, Chou MW. Human liver microsomal reduction of pyrrolizidine alkaloid $\mathrm{N}$-oxides to form the corresponding carcinogenic parent alkaloid. Toxicol Lett 2005; 155: 411-420

[46] Xia Q, Chou MW, Edgar JA, Doerge DR, Fu PP. Formation of DHP-derived DNA adducts from metabolic activation of the prototype heliotridinetype pyrrolizidine alkaloid, lasiocarpine. Cancer Lett 2006; 231: 138-145

[47] Xia Q, Zhao Y, Von Tungeln LS, Doerge DR, Lin G, Cai L, Fu PP. Pyrrolizidine alkaloid-derived DNA adducts as a common biological biomarker of pyrrolizidine alkaloid-induced tumorigenicity. Chem Res Toxicol 2013; 26: 1384-1396

[48] Yang YC, Yan J, Doerge DR, Chan PC, Fu PP, Chou MW. Metabolic activation of the tumorigenic pyrrolizidine alkaloid, riddelliine, leading to DNA adduct formation in vivo. Chem Res Toxicol 2001; 14: 101-109

[49] Prakash AS, Pereira TN, Reilly PE, Seawright AA. Pyrrolizidine alkaloids in human diet. Mutat Res 1999; 443: 53-67

[50] Uhl M, Helma C, Knasmüller S. Evaluation of the single cell gel electrophoresis assay with human hepatoma (Hep G2) cells. Mutat Res 2000; 468: $213-225$

[51] Louisse J, Rijkers D, Stoopen G, Holleboom WJ, Delagrange M, Molthof E, Mulder PP, Hoogenboom RL, Audebert M, Peijnenburg AA. Determination of genotoxic potencies of pyrrolizidine alkaloids in HepaRG cells using the $\mathrm{yH} 2 \mathrm{AX}$ assay. Food Chem Toxicol 2019; 131: 110532

[52] Cleaver JE, Feeney L, Revet I. Phosphorylated H2Ax is not an Unambiguous Marker for DNA Double-Strand Breaks. In: Taylor \& Francis; 2011

[53] de Feraudy S, Revet I, Bezrookove V, Feeney L, Cleaver JE. A minority of foci or pan-nuclear apoptotic staining of $\mathrm{\gamma H} 2 \mathrm{AX}$ in the $\mathrm{S}$ phase after UV damage contain DNA double-strand breaks. PNAS 2010; 107: 68706875

[54] Audebert M, Riu A, Jacques C, Hillenweck A, Jamin E, Zalko D, Cravedi JP. Use of the $\mathrm{yH} 2 \mathrm{AX}$ assay for assessing the genotoxicity of polycyclic aromatic hydrocarbons in human cell lines. Toxicol Lett 2010; 199: 182-192

[55] Khoury L, Zalko D, Audebert M. Validation of high-throughput genotoxicity assay screening using $\mathrm{\gamma H} 2 \mathrm{AX}$ in-cell western assay on HepG2 cells. Environ Mol Mutagen 2013; 54: 737-746

[56] Mah L, El-Osta A, Karagiannis T. $\gamma \mathrm{H} 2 \mathrm{AX}$ : a sensitive molecular marker of DNA damage and repair. Leukemia 2010; 24: 679-686

[57] Pinto DMS, Flaus A. Structure and Function of Histone H2AX. In: Nasheuer HP, eds. Genome Stability and Human Diseases. Subcellular Biochemistry, Vol 50. Dordrecht: Springer; 2010: 55-78

[58] Chou MW, Wang YP, Yan J, Yang YC, Beger RD, Williams LD, Doerge DR, Fu PP. Riddelliine N-oxide is a phytochemical and mammalian metabolite with genotoxic activity that is comparable to the parent pyrrolizidine alkaloid riddelliine. Toxicol Lett 2003; 145: 239-247

[59] EFSA; Knutsen HK, Alexander ], Barregård L, Bignami M, Brüschweiler B, Ceccatelli S, Cottrill B, Dinovi M, Edler L. Risks for human health related to the presence of pyrrolizidine alkaloids in honey, tea, herbal infusions and food supplements. EFSA J 2017; 15: e04908

[60] Merz KH, Schrenk D. Interim relative potency factors for the toxicological risk assessment of pyrrolizidine alkaloids in food and herbal medicines. Toxicol Lett 2016; 263: 44-57

[61] NTP. Bioassay of lasiocarpine for possible carcinogenicity. Natl Cancer Inst Carcinog Tech Rep Ser 1978; 39: 1-66 
[62] NTP. Toxicology and Carcinogenesis Studies of Riddelliine in F344/N Rats and B6C3F1 Mice. NTP Technical Report (CAS No. 23246-96-0). 2001

[63] Kirsch-Volders M. Towards a validation of the micronucleus test. Mutat Res 1997; 392: 1-4

[64] Bouquet F, Muller C, Salles B. The loss of $\gamma \mathrm{H} 2 \mathrm{AX}$ signal is a marker of DNA double strand breaks repair only at low levels of DNA damage. Cell Cycle 2006; 5: 1116-1122

[65] Imreh G, Norberg HV, Imreh S, Zhivotovsky B. Chromosomal breaks during mitotic catastrophe trigger $\mathrm{\gamma H} 2 \mathrm{AX}-\mathrm{ATM}-\mathrm{p} 53$-mediated apoptosis. J Cell Sci 2011; 124: 2951-2963

[66] Revet I, Feeney L, Bruguera S, Wilson W, Dong TK, Oh DH, Dankort D, Cleaver JE. Functional relevance of the histone $\mathrm{yH} 2 \mathrm{Ax}$ in the response to DNA damaging agents. PNAS 2011; 108: 8663-8667

[67] Harada A, Matsuzaki K, Takeiri A, Mishima M. The predominant role of apoptosis in $\mathrm{yH} 2 \mathrm{AX}$ formation induced by aneugens is useful for distinguishing aneugens from clastogens. Mutat Res 2014; 771: 23-29

[68] Bekeschus S, Schütz CS, Nießner F, Wende K, Weltmann KD, Gelbrich N, von Woedtke T, Schmidt A, Stope MB. Elevated H2AX phosphorylation observed with kINPen plasma treatment is not caused by ROS-mediated DNA damage but is the consequence of apoptosis. Oxid Med Cell Longev 2019: 8535163. doi:10.1155/2019/8535163

[69] Fashe MM, Juvonen RO, Petsalo A, Rasanen J, Pasanen M. Species-specific differences in the in vitro metabolism of lasiocarpine. Chem Res Toxicol 2015; 28: 2034-2044

[70] Li N, Xia Q, Ruan J, Fu PP, Lin G. Hepatotoxicity and tumorigenicity induced by metabolic activation of pyrrolizidine alkaloids in herbs. Curr Drug Metab 2011; 12: 823-834

[71] Miranda CL, Reed RL, Guengerich FP, Buhler DR. Role of cytochrome P450IIIA4 in the metabolism of the pyrrolizidine alkaloid senecionine in human liver. Carcinogenesis 1991; 12: 515-519
[72] Mueller D, Krämer L, Hoffmann E, Klein S, Noor F. 3D organotypic HepaRG cultures as in vitro model for acute and repeated dose toxicity studies. Toxicology in Vitro 2014; 28: 104-112

[73] Gómez-Lechón M], Tolosa L, Conde I, Donato MT. Competency of different cell models to predict human hepatotoxic drugs. Expert Opin Durg Metab Toxicol 2014; 10: 1553-1568

[74] Kovach JS, Ames MM, Powis G, Moertel CG, Hahn RG, Creagan ET. Toxicity and pharmacokinetics of a pyrrolizidine alkaloid, indicine N-oxide, in humans. Cancer Res 1979; 39: 4540-4544

[75] Xiong A, Li Y, Yang L, Gao J, He Y, Wang C, Wang Z. Simultaneous determination of senecionine, adonifoline and their metabolites in rat serum by UPLC-ESIMS and its application in pharmacokinetic studies. J Pharm Biomed Anal 2009; 50: 1070-1074

[76] Wang C, Li Y, Gao J, He Y, Xiong A, Yang L, Cheng X, Ma Y, Wang Z. The comparative pharmacokinetics of two pyrrolizidine alkaloids, senecionine and adonifoline, and their main metabolites in rats after intravenous and oral administration by UPLC/ESIMS. Anal Bioanall Chem 2011; 401: 275-287

[77] Long F, Ji J, Wang X, Wang L, Chen T. LC-MS/MS method for determination of seneciphylline and its metabolite, seneciphylline $\mathrm{N}$-oxide in rat plasma and its application to a rat pharmacokinetic study. Biomed Chromatogr 2021; 35: e5145

[78] Estep J, Lame M, Morin D, Jones A, Wilson DW, Segall H. [14C] monocrotaline kinetics and metabolism in the rat. Drug Metab Dispos 1991; 19: 135-139

[79] Chen L, Zhang B, Liu J, Fan Z, Weng Z, Geng P, Wang X, Lin G. Pharmacokinetics and bioavailability study of monocrotaline in mouse blood by ultra-performance liquid chromatography-tandem mass spectrometry. Biomed Res Int 2018: 1578643. doi:10.1155/2018/1578643 